\title{
Kinetics and mechanism for degradation of dichlorvos by permanganate in drinking water treatment
}

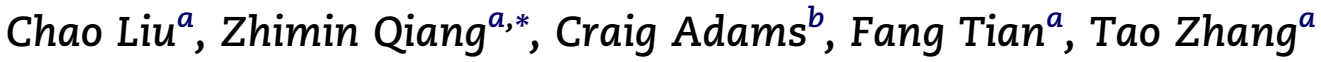 \\ ${ }^{a}$ Research Center for Eco-Environmental Sciences (RCEES), Chinese Academy of Sciences, 18 Shuang-qing Road, \\ Hai-dian District, Beijing 100085, China \\ ${ }^{\mathrm{b}}$ Department of Civil, Environmental and Architectural Engineering, University of Kansas, Lawrence, KS 66045, USA
}

\section{A R T I C L E I N F O}

Article history:

Received 12 January 2009

Received in revised form

1 May 2009

Accepted 5 May 2009

Published online 14 May 2009

\section{Keywords:}

Dichlorvos

Permanganate

Kinetics

Mechanism

Drinking water treatment

\begin{abstract}
A B S T R A C T
The degradation kinetics and mechanism of dichlorvos by permanganate during drinking water treatment were investigated. The reaction of dichlorvos with permanganate was of second-order overall with negligible $\mathrm{pH}$ dependence and an activation energy of $29.5 \mathrm{~kJ} \cdot \mathrm{mol}^{-1}$. At pH 7.0 and $25^{\circ} \mathrm{C}$, the rate constant was $25.2 \pm 0.4 \mathrm{M}^{-1} \mathrm{~s}^{-1}$. Dichlorvos was first degraded to trimethyl phosphate (TMP) and dimethyl phosphate (DMP) simultaneously which approximately accounted for $<5 \%$ and $\geq 95 \%$ with respect to phosphorus mass, respectively. Further oxidation of DMP generated a final byproduct, monomethyl phosphate (MMP). MMP was for the first time identified as a major byproduct in chemical oxidation of dichlorvos. The kinetic model based on degradation mechanism and determined reaction rate constants allowed us to predict the evolution of dichlorvos and its byproduct concentrations during permanganate pre-oxidation process at water treatment plants. These results suggest that even though the dichlorvos concentration in surface water complies with the surface water quality standards of China $\left(50 \mu \mathrm{g} \mathrm{L}^{-1}\right)$, its concentration after conventional water treatment will most probably exceed the drinking water quality standards $\left(1 \mu \mathrm{g} \mathrm{L}^{-1}\right)$. Moreover, luminescent bacteria test shows that the acute toxicity of dichlorvos solution evidently increased after permanganate oxidation.
\end{abstract}

(c) 2009 Elsevier Ltd. All rights reserved.

\section{Introduction}

Dichlorvos, O-2,2-dichlorovinyl-O,O-dimethyl phosphate (DDVP), is a chlorinated organophosphate insecticide that is extensively used in many countries for controlling insect pests on agricultural, commercial, domestic, and industrial sites (Gan et al., 2006). Compared to other pesticides, dichlorvos is generally preferred because of its cost-effectiveness and wide range of bioactivity. Its annual worldwide sales in 2003 were about 40 million U.S. dollars (Zhang et al., 2007). In China, an estimated demand was over 40,000 tons in 2007 , and its usage is expected to increase since five highly toxic organophosphate insecticides (e.g., parathion) have been recently banned. Dichlorvos is a mutagen and a suspected carcinogen for human beings. The LC50 value shows that dichlorvos has a high acute toxicity (U.S. Environmental Protection Agency, 2006). To reduce its potential threat to human beings via drinking water, drinking water quality standards have been set by various states or organizations. For instance, the maximum contaminant level (MCL) for dichlorvos is set at $1 \mu \mathrm{g} \mathrm{L}^{-1}$ in China (Ministry of Public Health of China, 2006), and the European Union (E.U.) drinking water standards regulate

\footnotetext{
* Corresponding author. Tel.: +86 106284 9632; fax: +86 1062923541.

E-mail address: qiangz@rcees.ac.cn (Z. Qiang). 
an MCL for any particular pesticide at $0.1 \mu \mathrm{gL}^{-1}$ and the sum of all pesticides at $0.5 \mu \mathrm{g} \mathrm{L}^{-1}$, including the degradation byproducts (E.U., 2007).

The abundant use of dichlorvos and two other pesticides, naled and trichlorfon which can be degraded to dichlorvos (U.S. Environmental Protection Agency, 2006; Zhang et al., 2007), indicates that the occurrence of dichlorvos in water resources may be expected. Gao et al. (2009) have recently reported that dichlorvos was the most frequently detected organophosphate pesticide in the surface water samples collected from 600 sites around China. The detection frequency of dichlorvos was as high as $89.1 \%$, and its peak concentration was $1552.0 \mathrm{ng} \mathrm{L}^{-1}$ in Yangtze River. It is seen that dichlorvos is undoubtedly a major organophosphate pesticide contaminant in the surface water of China. Once the level of dichlorvos in raw waters does not meet regulations, additional treatment processes have to be applied to comply with the drinking water standards. Treatment methods such as biodegradation (Lieberman and Alexander, 1983), ultrasonication (Schramm and Hua, 2001), adsorption (Lu et al., 1996), photocatalysis (Lu et al., 1993; Evgenidou et al., 2005, 2006), and oxidation with Fenton's reagent and permanganate (Lu et al., 1997, 1999; Waldemer and Tratnyek, 2006) have shown effectiveness on the decomposition of dichlorvos. Among the above various treatment methods, permanganate oxidation is commonly used at water treatment plants due to the stability, ease of handling, wide $\mathrm{pH}$ range, and low cost of the oxidant. Especially in China, permanganate has been employed as a pre-oxidation chemical to eliminate taste and odor, and remove algae (Ma et al., 1997). In addition, it is effective in enhancing coagulation and controlling the formation potential of trihalomethanes and other disinfection byproducts (DBPs) in drinking water treatment (Ma et al., 1997; Rodríguez et al., 2007).

Although the oxidation of dichlorvos by permanganate was investigated with the proposal of second-order rate constant (Waldemer and Tratnyek, 2006), there was still lack of information about the degradation kinetics and mechanism. In particular, the qualitative and quantitative data of degradation byproducts during the oxidation process will allow assessing the treatment effectiveness with respect to drinking water regulations. Therefore, this work primarily aimed to establish a kinetic model to predict the evolution of dichlorvos and its degradation byproducts during permanganate oxidation process. The following steps were required: 1) kinetics for the reaction of dichlorvos with permanganate; 2) identification of major degradation byproducts; 3 ) determination of rate constant of each identified byproduct with permanganate; and 4) development and application of the kinetic model to drinking water treatment. In addition, the variation of acute toxicity of dichlorvos solution during permanganate oxidation process was also examined.

\section{Materials and methods}

\subsection{Standards and reagents}

Dichlorvos (99.5\%) was purchased from Chem Service. Trimethyl phosphate (TMP) (99\%) and dimethyl phosphate (DMP)
(98\%) were obtained from Acros. Monomethyl phosphate (MMP) (97.5\%) and N,O-bis(trimethylsilyl)-trifluoroacetamide (BSTFA) containing 1\% trimethylchlorosilane (TMCS) were purchased from Sigma-Aldrich. Other chemicals were of at least analytical grade and used as received.

\subsection{Analytical methods}

Dichlorvos was determined with gas chromatography/mass spectrometry (GC/MS, 7890 GC and 5975 MSD, Agilent) equipped with an HP-5 MS column $(30 \mathrm{~m} \times 0.25 \mathrm{~mm} \times 0.25 \mu \mathrm{m}$ film thickness). Helium gas was used as carrier gas at a flow rate of $1 \mathrm{~mL} \mathrm{~min}{ }^{-1}$. The oven temperature started at $40^{\circ} \mathrm{C}$ and ramped linearly to $280^{\circ} \mathrm{C}$ at $30^{\circ} \mathrm{C} \mathrm{min}{ }^{-1}$. The MS detector was operated in the electron ionization (EI) mode with a potential of $70 \mathrm{eV}$. The quantification and confirmation ions used in the selective ion mode (SIM) were 220, 185 and $109(\mathrm{~m} / \mathrm{z})$ with a detection limit of $0.1 \mu \mathrm{M}$.

TMP was analyzed by liquid chromatography/mass spectrometry (LC/MS, 2695 HPLC and ZQ 4000 MSD, Waters) equipped with an Atlantis dC18 column (Waters). The eluent contained $90 \%$ water and $10 \%$ acetonitrile (flow rate $=$ $0.2 \mathrm{~mL} \mathrm{~min}^{-1}$ ). The spectra were acquired in the electrospray interface positive scan mode (ESI+). The quantification and confirmation ions used in the selective ion recording (SIR) mode were 141, 163 and 179 which corresponded to the protonated ion, sodium and potassium adducts, respectively. The detection limit of TMP was $0.005 \mu \mathrm{M}$.

DMP and MMP were analyzed according to Kozlova et al. (2004) with certain modification. Each $5 \mathrm{~mL}$ of aqueous solution of DMP and MMP was prepared at different concentration levels (from 0.02 to $1.00 \mu \mathrm{M}$ ) in a glass tube with cuspate bottom and then evaporated in a vacuumed rotary evaporator until dryness in $40^{\circ} \mathrm{C}$ water bath. The $\mathrm{pK}_{\mathrm{a}}$ values of DMP and MMP are 1.25 (Schramm and Hua, 2001) and below 7.0 (Lad et al., 2003), respectively. Considering that the undissociated acids might volatilize during the vacuum evaporation process, the solution was pre-adjusted to $\mathrm{pH} 7.7$ with borate buffer to keep DMP and MMP in the form of ions and thus minimize their volatilization. After evaporation, $100 \mu \mathrm{L}$ of BSTFA and $100 \mu \mathrm{L}$ of pyridine were added to the resulting powder. The capped tube was vortexed for $20 \mathrm{~s}$ and heated in $60^{\circ} \mathrm{C}$ water bath for $30 \mathrm{~min}$. The mixture was allowed to cool down to room temperature, and the residual BSTFA and pyridine were blown off under a slight stream of nitrogen. Finally, the derivatives were dissolved in $0.5 \mathrm{~mL}$ of hexane and analyzed by GC/MS. The GC oven temperature started at $40^{\circ} \mathrm{C}$ and held for $2 \mathrm{~min}$, ramped at $3^{\circ} \mathrm{C} \mathrm{min}{ }^{-1}$ to $100^{\circ} \mathrm{C}$ and held for $5 \mathrm{~min}$, ramped at $5^{\circ} \mathrm{Cmin}^{-1}$ to $150^{\circ} \mathrm{C}$, and further ramped at $20^{\circ} \mathrm{C} \mathrm{min}^{-1}$ to $290^{\circ} \mathrm{C}$. The quantification and confirmation ions used in the SIM mode were as follows: 198, 183, 153 (DMP); and 256, 241, 211 (MMP). The calibration curves of both DMP and MMP in the concentration range from 0.02 to $1.00 \mu \mathrm{M}$ showed a good linearity $\left(R^{2}>0.99\right)$. The detection limits of DMP and MMP were about $0.01 \mu \mathrm{M}$.

The concentration of chloride ion was measured with Metrohm 861 ion chromatography (IC). Dichloroaldehyde was analyzed according to Gan et al. (2006), and dichloroacetic acid was determined according to U.S. EPA method 552.2 . 


\subsection{Reaction kinetics of dichlorvos with permanganate}

Several experimental series were carried out in distilled water by altering the reactant concentration, $\mathrm{pH}$, and temperature under pseudo-first-order conditions where permanganate was at least 10 -fold in excess. Initial concentrations were varied in the range of $60-100 \mu \mathrm{M}$ for permanganate and $5-10 \mu \mathrm{M}$ for dichlorvos. The $\mathrm{pH}$ was varied at 6.0 , 7.0 and 8.0 with $50 \mathrm{mM}$ phosphate buffer, and the temperature ranged from 5 to $35^{\circ} \mathrm{C}$. The reaction was initiated by injection of $0.6-1.0 \mathrm{~mL}$ of permanganate stock solution $(10 \mathrm{mM})$ into $100 \mathrm{~mL}$ of fresh dichlorvos solution $(5-10 \mu \mathrm{M})$. Samples were withdrawn at preselected intervals, quenched immediately with sulfite, and filtered through a $0.45-\mu \mathrm{m}$ cellulose filter. Each $5 \mathrm{~mL}$ of aqueous sample was extracted with $2 \mathrm{~mL}$ of methyl tert-butyl ether (MTBE) immediately after filtration and then analyzed by GC/MS to determine the residual dichlorvos.

\subsection{Byproduct identification}

To determine the evolution of dichlorvos and its byproducts, the reaction was performed at $\mathrm{pH} 7.7$ (5 mM borate buffer) and $25{ }^{\circ} \mathrm{C}$ in distilled water. After addition of permanganate stock solution, the reaction started with the initial concentrations of $25 \mu \mathrm{M}$ for permanganate and $1 \mu \mathrm{M}$ for dichlorvos. Samples were withdrawn regularly, quenched and filtered immediately, and then analyzed by LC/MS for TMP. In addition, each $5 \mathrm{~mL}$ of filtered sample was extracted with $2 \mathrm{~mL}$ of MTBE. The extract was analyzed by GC/MS to determine the residual dichlorvos. DMP and MMP in aqueous layer existed primarily in the form of ions at $\mathrm{pH}$ 7.7, so partitioning of these acids into the MTBE phase were negligible (Schramm and Hua, 2001). Then DMP and MMP were analyzed with the aforementioned procedures.

Experiments were also carried out in filtered surface water collected from Jingmi Trench in Beijing, China. The main water quality parameters were as follows: $\mathrm{pH}=8.2$, dissolved organic carbon $(\mathrm{DOC})=9.7 \mathrm{mgL}^{-1}$, alkalinity $=1.5 \mathrm{mM}$. The waters were filtered with $0.45-\mu \mathrm{m}$ cellulose acetate filters and then the same procedure was performed as that in distilled water except the initial concentrations of dichlorvos and permanganate. Dichlorvos was spiked at a relatively low concentration of $0.5 \mu \mathrm{M}$. The initial permanganate concentration was $9.4 \mu \mathrm{M}$ (i.e., $1.5 \mathrm{mgL}^{-1}$ ), a typical dosage in pre-oxidation process during drinking water treatment. The residual concentration of permanganate was determined with the DPD method (Rodríguez et al., 2007).

\subsection{Determination of reaction rate constants of byproducts with permanganate}

The rate constants for the reactions of dichlorvos degradation byproducts with permanganate were determined by monitoring the permanganate decay in at least 10 -fold excess of target byproduct at $\mathrm{pH} 7.7$ and $25^{\circ} \mathrm{C}$ according to the pseudofirst-order kinetics. Permanganate concentration was measured by the DPD method.

\subsection{Toxicity measurement}

The acute toxicity of the samples collected at specific reaction time intervals was examined by means of luminescent bacteria (Photobacterium phosphoreum $\mathrm{T}_{3}$ spp.) test following the procedures described in the national water quality standards of China (Ministry of Environmental Protection of China, 1995). Due to the limitation of the analytical method, higher initial concentrations of dichlorvos $(90 \mu \mathrm{M})$ and permanganate $(300 \mu \mathrm{M})$ were adopted in the experiments with distilled water and filtered surface water from Jingmi Trench, even though their concentrations were much greater than those at water treatment plants. The residual permanganate in the samples was immediately quenched with $75 \mathrm{mgL}^{-1}$ sodium sulfite prior to analysis. Our preliminary experiments have shown that at this level, sodium sulfite exerted negligible toxic effect on luminescent bacteria.

\section{Results and discussion}

\subsection{Reaction order and rate constants of dichlorvos with permanganate}

The reaction law of dichlorvos with permanganate was first investigated in this study under pseudo-first-order conditions (i.e., at least a 10:1 molar ratio of permanganate to dichlorvos) in a batch system. The reaction between dichlorvos and permanganate can be written as follows:

DDVP $+n \mathrm{KMnO}_{4} \rightarrow$ products

Under the pseudo-first-order conditions, the rate of dichlorvos oxidation is simplified to Eqs. (2) and (3):

$-d[D D V P] / d t=k^{\prime}[D D V P]$

and

$\ln \left(k^{\prime}\right)=\ln (k)+n \ln \left(\left[\mathrm{KMnO}_{4}\right]_{0}\right)$

where $k^{\prime}$ and $k$ represent the reaction rate constants. A plot of $\ln \left(k^{\prime}\right)$ vs. $\ln \left(\left[\mathrm{KMnO}_{4}\right]_{0}\right)$ will yield a straight line, accordingly with the slope denoting $n$ (i.e., the stoichiometric number). Table 1 summarized the values of $k^{\prime}$ obtained in various initial permanganate concentrations. A plot of $\ln \left(k^{\prime}\right)$ vs. $\ln \left(\left[\mathrm{KMnO}_{4}\right]_{\circ}\right)$ gives a linear curve with the slope (i.e., $n$ ) almost equaling 1.0 (Fig. 1). Thus, the reaction between dichlorvos and permanganate was of second-order in total and first-order with respect to each reactant. Using Eq. (3), a second-order rate

Table 1 - Pseudo-first-order rate constants for the reaction of dichlorvos with permanganate at various initial reactant concentrations $\left(\mathrm{pH}=7.0, \mathrm{~T}=25^{\circ} \mathrm{C}\right.$, $\mathrm{I} \approx \mathbf{0 . 0 1} \mathrm{M}$ ).

\begin{tabular}{lccc}
{$[\mathrm{DDVP}]_{\circ}(\mu \mathrm{M})$} & {$\left[\mathrm{KMnO}_{4}\right]_{\circ}(\mu \mathrm{M})$} & $k^{\prime} \times 10^{4}\left(\mathrm{~s}^{-1}\right)$ & $R^{2}$ \\
\hline 5 & 60 & 14.9 & 0.994 \\
7 & 70 & 18.3 & 0.995 \\
7 & 85 & 21.4 & 0.993 \\
10 & 100 & 25.0 & 0.994 \\
\hline
\end{tabular}




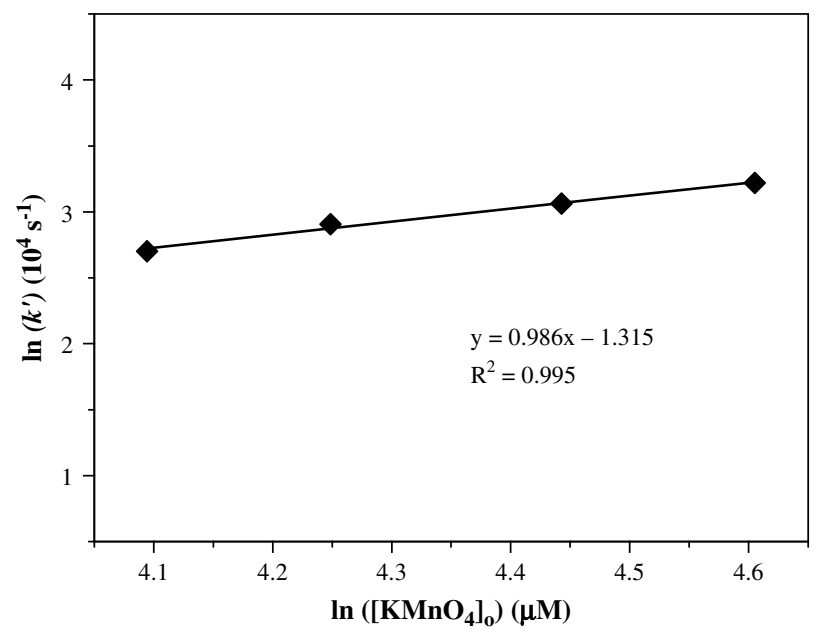

Fig. 1 - Plot of $\ln \left(k^{\prime}\right)$ vs. $\ln \left(\left[\mathrm{KMnO}_{4}\right]_{\mathrm{o}}\right)$. Experimental conditions: $\mathrm{pH}=7.0, \mathrm{~T}=25^{\circ} \mathrm{C}$.

constant of $25.2 \pm 0.4 \mathrm{M}^{-1} \mathrm{~s}^{-1}$ at $\mathrm{pH} 7.0$ and $25^{\circ} \mathrm{C}$ was deduced. The hydrolysis of dichlorvos might also contribute to the decay of dichlorvos. However, a recent meticulous study reported that the rate constant of dichlorvos hydrolysis was $3.72 \times 10^{-6} \mathrm{~s}^{-1}$, equivalent to a half-life of $51.7 \mathrm{~h}$ at $\mathrm{pH} 7.15$ (Gan et al., 2006). It indicates that the hydrolysis of dichlorvos can be neglected during the $0.5 \mathrm{~h}$ reaction time. In addition, the initial concentration of dichlorvos would not affect the rate constant determination in the case of pseudo-first-order simulation with at least 10 -fold excess of permanganate.

It is noted that our rate constant was slightly higher than the rate constant of $15.7 \pm 0.4 \mathrm{M}^{-1} \mathrm{~s}^{-1}$ determined by Waldemer and Tratnyek (2006) at the same $\mathrm{pH}$ and temperature. They measured the decay of permanganate absorbance in a continuous system with at least 10 -fold excess of dichlorvos. In this case, the initial concentration of dichlorvos may notably affect the rate constant determination. If an aged dichlorvos solution was used, its experimental concentration would be lower than its initial concentration due to dichlorvos hydrolysis. As a result, the rate constant calculated from the nominal initial concentration of dichlorvos would be underestimated.

\subsection{Effect of $p H$}

Fig. 2 represents the change of normalized residual dichlorvos concentration vs. reaction time at $\mathrm{pH} 6.0,7.0$ and 8.0, individually. The residual dichlorvos concentrations for different $\mathrm{pHs}$ at any reaction time were very similar, indicating that $\mathrm{pH}$ influence was negligible on degradation rate, at least in the investigated range. It was also reported that for some nondissociating organic compounds (e.g., MTBE), the reaction rates with permanganate did not show any $\mathrm{pH}$ dependence in the neutral $\mathrm{pH}$ range (Damm et al., 2002). Therefore, no $\mathrm{pH}$ adjustment is required for dichlorvos removal by permanganate at water treatment plants.

\subsection{Effect of temperature}

The effect of temperature on the rate constant for reaction of dichlorvos with permanganate was investigated from 5 to

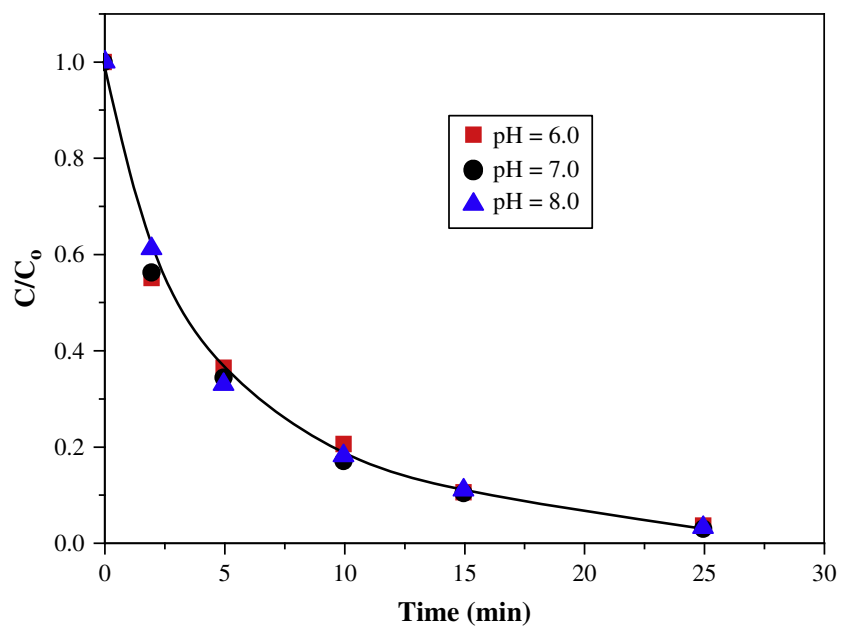

Fig. 2 - Effect of $\mathrm{pH}$ on dichlorvos degradation by permanganate. Experimental conditions: $\mathrm{T}=25^{\circ} \mathrm{C}$, $\left[\mathrm{KMnO}_{4}\right]_{\mathrm{o}}=100 \mu \mathrm{M},[\mathrm{DDVP}]_{\mathrm{o}}=10 \mu \mathrm{M}$.

$35^{\circ} \mathrm{C}$, representing the typical temperature condition in drinking water system (Qiang and Adams, 2004). A linearized Arrhenius equation:

$\ln (k)=\ln (\mathrm{A})-\mathrm{E}_{\mathrm{a}} / \mathrm{RT}$

was used to calculate the activation energy by means of the second-order rate constants at different temperatures. Plotting $\ln (k)$ vs. $1 /$ T would yield a linear curve and the slope gives " $-E_{a} / R$ ", as shown in Fig. 3. Therefore, the activation energy value of $29.5 \mathrm{~kJ} \mathrm{~mol}^{-1}$ for the reaction of dichlorvos with permanganate was calculated. According to this value, a $10^{\circ} \mathrm{C}$ temperature increase results in a reaction rate constant increase by a factor of around 1.5. This activation energy is similar to the value of $28.8 \mathrm{~kJ} \mathrm{~mol}^{-1}$ for the oxidation of microcystins by permanganate (Rodríguez et al., 2007).

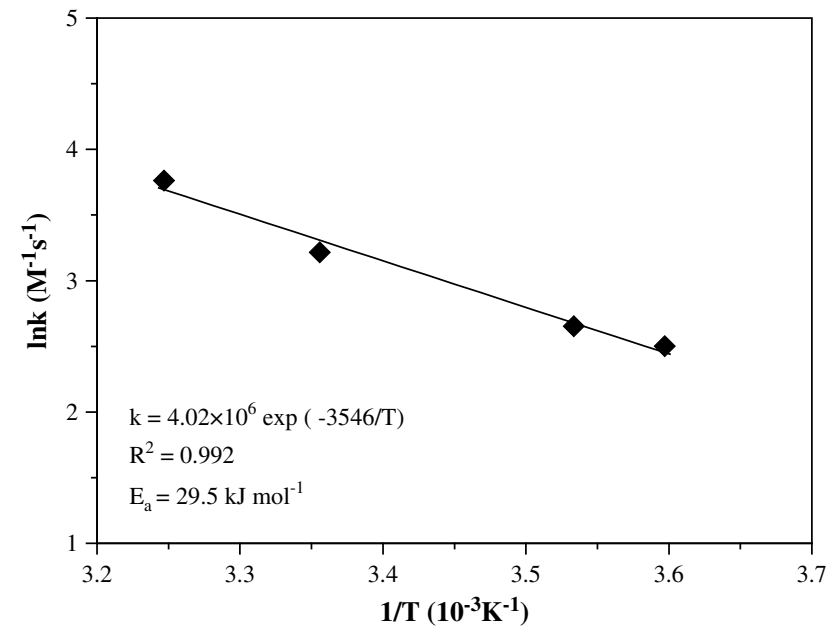

Fig. 3 - Arrhenius plot of the rate constants for the reaction of dichlorvos with permanganate at different temperatures. Experimental conditions: $\mathrm{pH}=7.0$, $\mathrm{I} \approx 0.01 \mathrm{M},\left[\mathrm{KMnO}_{4}\right]_{\mathrm{o}}=100 \mu \mathrm{M},[\mathrm{DDVP}]_{\mathrm{o}}=10 \mu \mathrm{M}$. The standard deviation for all data points was below $5 \%$. 


\subsection{Byproduct formation}

Fig. 4 shows the evolution of the concentrations of dichlorvos and its degradation byproducts during the oxidation of dichlorvos by permanganate. Results indicate that DMP and MMP were two major degradation byproducts, while TMP was a minor byproduct. During the first $5 \mathrm{~min}$, dichlorvos was degraded to TMP and DMP which approximately accounted for $<5 \%$ and $\geq 95 \%$ with respect to phosphorus mass, respectively, indicating that DMP and TMP could be the first generation of the degradation byproducts. As the reaction proceeded from 5 to $90 \mathrm{~min}$, DMP accumulated unceasingly and the MMP concentration increased to a significant level. When dichlorvos degradation was almost complete (around $1.5 \mathrm{~h}$ ), the DMP concentration increased to an apex. Within the reaction time from 1.5 to $6.0 \mathrm{~h}$, the slow decrease in DMP concentration indicates that DMP was further degraded by permanganate, whereas its reactivity toward permanganate was much lower than that of dichlorvos. Furthermore, the continuous increase in MMP concentration in the absence of dichlorvos indicates that MMP was the second generation of the degradation byproducts (i.e., from DMP). MMP was first identified as a major byproduct and quantified during the oxidation of dichlorvos in this study. A mass balance on phosphorus ranging from about 90 to 105\% (Fig. 4), which was calculated from the mean concentrations of DDVP, TMP, DMP and MMP at various reaction times, infers that the major byproducts have been accounted for in this work.

The hydrolysis of TMP is not of concern during chemical oxidation processes (Kozlova et al., 2004). Both DMP and MMP strongly resist hydrolysis. Wolfenden et al. (1998) reported that the first-order rate constants at $\mathrm{pH} 7.0$ and $25^{\circ} \mathrm{C}$ for DMP and MMP hydrolysis were $1.6 \times 10^{-13}$ and $4.6 \times 10^{-14} \mathrm{~s}^{-1}$, respectively, equivalent of the half-lives more than $1 \times 10^{5}$ years. Therefore, the hydrolysis of dichlorvos degradation byproducts is negligible.

In addition, TMP and DMP were also identified as degradation byproducts of other organophosphate insecticides

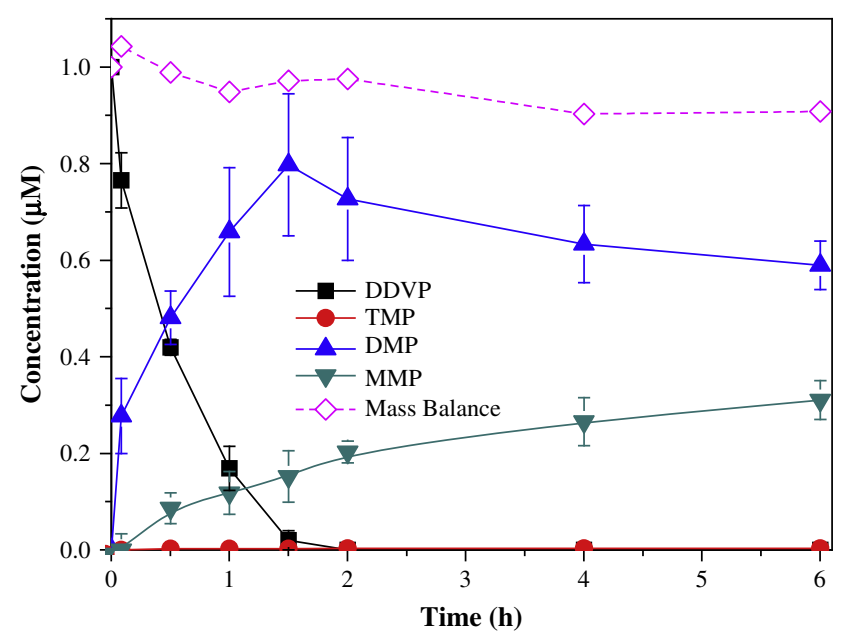

Fig. 4 - Evolution of the concentrations of dichlorvos and its degradation byproducts during permanganate oxidation in distilled water. Experimental conditions: $\mathrm{pH}=7.7$, $\mathrm{T}=25^{\circ} \mathrm{C},\left[\mathrm{KMnO}_{4}\right]_{\mathrm{o}}=25 \mu \mathrm{M},[\mathrm{DDVP}]_{\mathrm{o}}=1 \mu \mathrm{M}$. during chemical oxidation processes, including dimethoate (Evgenidou et al., 2006), fenitrothion (Ohashi et al., 1993), malathion (Dowling and Lemley, 1995) and methyl parathion (Vlyssides et al., 2004). As a result, it was proposed that TMP and DMP could be also generated from some organophosphates present as micropollutants during drinking water treatment. Due to the extensive usage of organophosphates, interests about the evolution of TMP and DMP concentrations during drinking water treatment should be raised seriously.

\subsection{Reaction rate constants of byproducts with permanganate}

To corroborate the reactivity obtained from Fig. 4, the reaction rate constants of dichlorvos degradation byproducts with permanganate were determined separately. Waldemer and Tratnyek (2006) have reported that the reactions of many contaminants with permanganate were of second-order in total and first-order with respect to each reactant, the reaction of dichlorvos with permanganate included. Therefore, the reactions of dichlorvos degradation byproducts with permanganate were reasonably expected to be of secondorder. The second-order rate constant was determined by measuring permanganate decay in at least 10-fold excess of target byproduct, as summarized in Table 2. It is seen that the oxidation of TMP by permanganate could be neglected due to its low concentration generated from dichlorvos degradation. DMP and MMP showed low reactivities toward permanganate as well, since these degradation byproducts lack electrondonating groups for permanganate attack. The relatively low reaction rate constants of DMP and MMP with permanganate agree well with results shown in Fig. 4.

\subsection{Proposed reaction mechanism}

On the basis of the identified byproducts and the reaction rate constants of byproducts with permanganate, the reaction mechanism between permanganate and dichlorvos is proposed, as shown in Fig. 5. Similar to Yan and Schwartz (2000) who investigated the oxidation of trichloroethylene by permanganate, the degradation of dichlorvos was initiated by the attack of permanganate on the dichlorovinyl moiety through a transition state (i.e., a cyclic hypomanganate ester) (Freeman and Kappod, 1985). The cyclic ester decomposed quickly and led to the formation of DMP. DMP could be further oxidized to MMP by permanganate, though with a relatively

Table 2 - Second-order rate constants for the reactions of dichlorvos and its degradation byproducts with permanganate $\left(\mathrm{pH}=7.7, \mathrm{~T}=25^{\circ} \mathrm{C}\right)$.

\begin{tabular}{lcc} 
Compounds & $k\left(\mathrm{M}^{-1} \mathrm{~s}^{-1}\right)^{\mathrm{a}}$ & $k\left(\mathrm{M}^{-1} \mathrm{~s}^{-1}\right)^{\mathrm{b}}$ \\
\hline DDVP & $25.2 \pm 0.4$ & $15.7 \pm 0.4$ \\
TMP & $<1.0$ & - \\
DMP & 0.8 & - \\
MMP & $<0.1$ & - \\
\hline
\end{tabular}

a Determined in this work.

b Reference (Waldemer and Tratnyek, 2006). 
<smiles>COP(=O)(OC)OC=C(Cl)Cl</smiles>

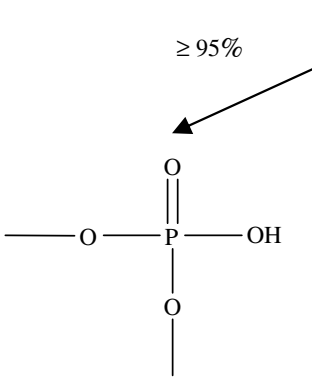

(DMP)

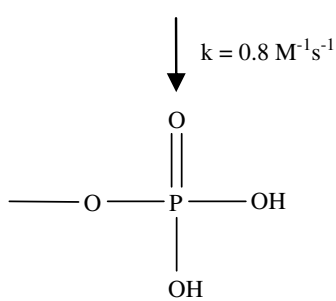

(MMP)

Fig. 5 - Proposed degradation mechanism of dichlorvos by permanganate.

lower rate constant of $0.8 \mathrm{M}^{-1} \mathrm{~s}^{-1}$. MMP could not be degraded any more within the reaction time of $6 \mathrm{~h}$ (Fig. 4).

Evgenidou et al. (2006) reported that a trace amount of TMP was detected in the photocatalytic oxidation of dichlorvos. In this work, it was also observed that only less than 5\% of dichlorvos was degraded to TMP by permanganate (Fig. 5). TMP was somewhat resistant to permanganate oxidation, showing a rate constant of less than $1.0 \mathrm{M}^{-1} \mathrm{~s}^{-1}$. Therefore, the formation of DMP was primarily ascribed to dichlorvos degradation instead of TMP degradation.

\subsection{Prediction for drinking water treatment}

Once the reaction pathway for the oxidation of dichlorvos by permanganate was established and the requisite rate constants were determined, a kinetic model could be proposed. It is a growing interest in application to be able to predict the degradation of dichlorvos and the formation of its degradation byproducts during the permanganate pre-oxidation process. For that, the permanganate exposure (concentration $\times$ time, or CT value) defined as the integral of permanganate concentration over the reaction time in natural waters should be determined. Accordingly, based on the above information, the concentrations of dichlorvos and its degradation byproducts can be calculated numerically by adopting second-order kinetics using Berkeley Madonna ${ }^{\circledR}$ computational software (Macey and Oster, 2005). Fig. 6 shows the experimental values (symbols) and model calculations (lines) for dichlorvos removal and byproduct formation during permanganate oxidation process in surface water. It should be noted that the formation of TMP was not taken into consideration in this kinetic model since it only accounted for less than $5 \%$ with respect to mass balance (Fig. 4). It was observed that the dichlorvos removal efficiency after 120 min oxidation was $74 \%$ (Fig. 6). Due to the low degradation level, only the formation of the first generation of degradation byproducts (i.e., DMP) was significant, which accounted for $70 \%$ with respect to the total phosphorus mass. A good coincidence between experimental values and model calculations supported this kinetic model to predict not only trace pollutant degradation, but also degradation byproducts formation during the permanganate pre-oxidation process.

This kinetic model is valuable for drinking water treatment. For instance, one can predict if the level of dichlorvos in raw waters is over $10 \mu \mathrm{gL}^{-1}$, a permanganate exposure of

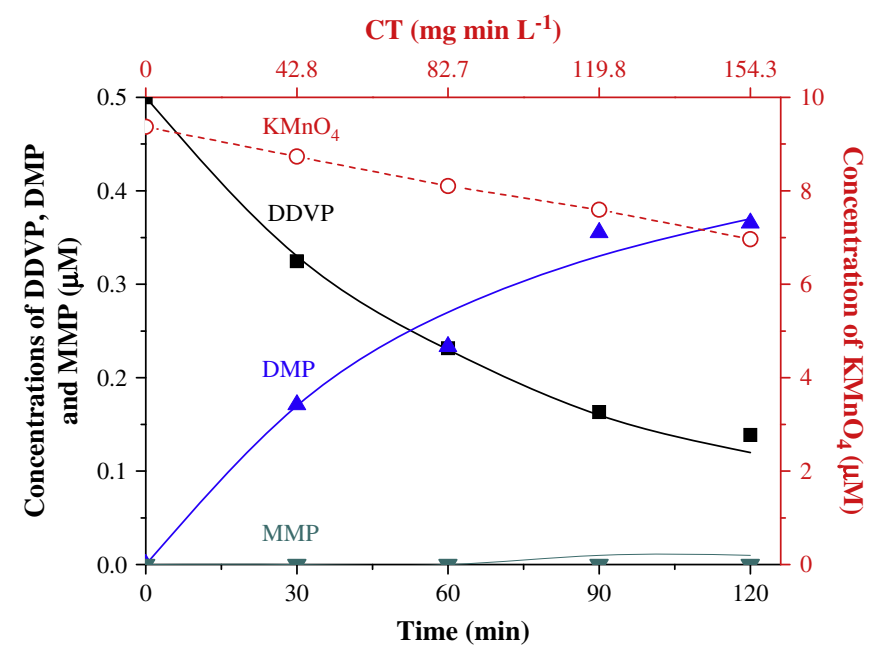

Fig. 6 - Evolution of the concentrations of dichlorvos and its degradation byproducts during permanganate oxidation in surface water. Experimental conditions: $\mathrm{pH}=7.7, \mathrm{~T}=25^{\circ} \mathrm{C},\left[\mathrm{KMnO}_{4}\right]_{\mathrm{o}}=9.4 \mu \mathrm{M},[\mathrm{DDVP}]_{\mathrm{o}}=0.5 \mu \mathrm{M}, \mathrm{DOC}=9.7 \mathrm{mg} \mathrm{L}{ }^{-1}$, alkalinity $=1.5 \mathrm{mM}$. 
$154.3 \mathrm{mg} \cdot \mathrm{min}^{-1}$ will still result in a dichlorvos concentration in the treated water above $2.5 \mu \mathrm{gL}^{-1}$. Considering the low $\log \mathrm{K}_{\mathrm{ow}}$ of dichlorvos (i.e., 1.16) (Schramm and Hua, 2001) and its low reactivity toward chlorine, conventional treatment processes (such as coagulation, filtration and chlorination) may not exhibit any significant dichlorvos control. Therefore, dichlorvos concentration in drinking water can be expected to be over $1 \mu \mathrm{gL}^{-1}$, and hence the standard for drinking water quality of China cannot be met. Furthermore, the MCL for dichlorvos in raw waters regulated in the environmental quality standards for surface water of China is $50 \mu \mathrm{gL}^{-1}$ (Ministry of Environmental Protection of China, 2002). It is possible that the treated water at most drinking water plants cannot conform to this standard even though the concentration of dichlorvos in raw waters is permissive (i.e., below $50 \mu \mathrm{gL}^{-1}$ ). In addition, for a more stringent regulation (e.g., E.U. regulation), once the level of dichlorvos in water resources is above $1 \mu \mathrm{gL}^{-1}$, the concentration of dichlorvos and its degradation byproducts in effluents can be expected to exceed $0.5 \mu \mathrm{g} \mathrm{L}^{-1}$, also indicating the regulation for pesticides could not be met.

These results were related to a practical case that recently occurred in Sichuan earthquake area of China in May, 2008. Dichlorvos was widely applied to control infectious diseases during the early period after the earthquake. However, its abundant usage led to the occurrence at a concerned level in surface waters (Ministry of Environmental Protection of China, 2008), which posed a severe threat to water treatment plants around. Therefore, the Ministry of Environmental Protection of China urgently banned dichlorvos in the earthquake area although it is permissive in China.

\subsection{Acute toxicity variation}

As aforementioned, dichlorvos has a high acute toxicity. A concern was promoted about the acute toxicity of dichlorvos solution after permanganate oxidation. Fig. 7 shows the results acquired by a bacterial luminescence test, where $I_{0}$ and

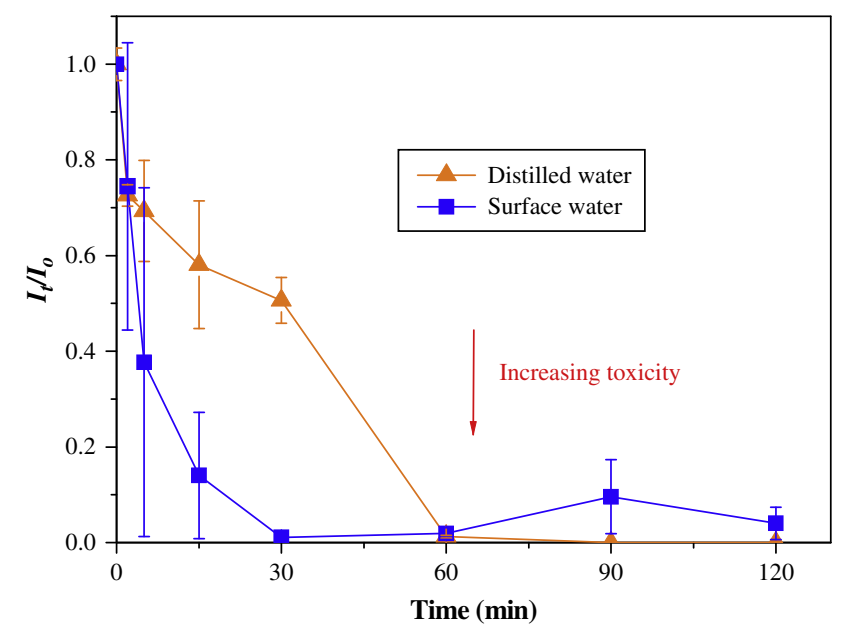

Fig. 7 - Variation of acute toxicity of dichlorvos solution during permanganate oxidation in distilled water and surface water. Experimental conditions: $\mathrm{pH}=7.0$, $\mathrm{T}=25^{\circ} \mathrm{C},\left[\mathrm{KMnO}_{4}\right]_{\mathrm{o}}=300 \mu \mathrm{M},[\mathrm{DDVP}]_{\mathrm{o}}=90 \mu \mathrm{M}$.
$I_{t}$ denoted the light production of samples withdrawn at reaction time 0 and $t$, respectively. The normalized light production decreased with the increase of reaction time in both distilled water and surface water, indicating that the toxicity of degradation byproducts increased. The toxicity of the surface water sample exhibited a more rapid enhancement than that of the distilled water sample, which might be ascribed to the influence of natural organic matters.

The enhanced toxicity of dichlorvos solution treated by photocatalytic oxidation was also reported (Lu et al., 1993; Evgenidou et al., 2005, 2006). Similarly, the enhanced toxicity in this study may be ascribed to the following reasons: 1) synergistic effect of organophosphorous esters on aquatic organisms and enzymes (Dzyadevych et al., 2002); 2) toxicity of unidentified chlorinated byproducts; and 3) suspected carcinogenicity of TMP (U.S. Department of Health, Education and Welfare, 1978). This enhanced toxicity may raise a reevaluation for the safety of drinking water when organophosphates, which can act as precursors to more toxic compounds, are present in source water as micropollutants.

The identification and quantification of chlorinated byproducts during chemical oxidation of dichlorvos were unsuccessful previously (Schramm and Hua, 2001; Evgenidou et al., 2006). Our results indicated that upon $94 \%$ of dichlorvos degradation by permanganate, the released chloride ion only accounted for about $40 \%$ of the total chloro mass initially present in dichlorvos molecule. We attempted to analyze potential chlorinated byproducts such as dichloroaldehyde and dichloroacetic acid, but did not detect any during the reaction course. The unbalanced chloro mass contained in unknown chlorinated byproducts requires more research efforts.

\section{Conclusions}

The reaction of dichlorvos with permanganate could be expressed by second-order kinetics. The reaction rate constant was determined to be $25.2 \pm 0.4 \mathrm{M}^{-1} \mathrm{~s}^{-1}$ at $\mathrm{pH} 7.0$ and $25^{\circ} \mathrm{C}$ and was independent of $\mathrm{pH}$ from 6.0 to 8.0. The activation energy was $29.5 \mathrm{~kJ} \mathrm{~mol}^{-1}$. Dichlorvos was first degraded by permanganate to TMP $(<5 \%)$ and DMP $(\geq 95 \%)$ with respect to phosphorus mass, respectively. Further degradation of DMP generated a final product MMP. These reactivities were corroborated by the determined rate constants for the reactions of dichlorvos degradation byproducts with permanganate.

The evolution of the concentrations of dichlorvos and its degradation byproducts during permanganate pre-oxidation process at water treatment plants could be predicted by the kinetic model developed in this study. Furthermore, the increased toxicity of dichlorvos solution after permanganate oxidation may arouse the concerns regarding drinking water safety when dichlorvos is present in source water as micropollutant. Additional research efforts are needed to identify and quantify unknown chlorinated byproducts.

\section{Acknowledgements}

This project was financially supported by National Natural Science Foundation of China (20677071), Key Technology R\&D 
Programs from Ministry of Science and Technology of China (2006BAJ08B02, 2006BAJ08B10), and the special fund from the State Key Laboratory of Environmental Aquatic Chemistry (08Z01ESPCR). The authors also thank Dr. Dongbin Wei for his help in acute toxicity analysis.

\section{R E F E R E N C E S}

Damm, J.H., Hardacre, C., Kalin, R.M., Walsh, K.P., 2002. Kinetics of the oxidation of methyl tert-butyl ether (MTBE) by potassium permanganate. Water Res. 36, 3638-3646.

Dowling, K.C., Lemley, A.T., 1995. Organophosphate insecticide degradation by non-amended and cupric ion-amended fentons reagent in aqueous-solution. J. Environ. Sci. Health, Part B: Pestic. Food Contam. Agric. Wastes 30, 585-604.

Dzyadevych, S.V., Soldatkin, A.P., Chovelon, J.M., 2002. Assessment of the toxicity of methyl parathion and its photodegradation byproducts in water samples using conductometric enzyme biosensors. Anal. Chim. Acta 459, $31-41$.

European Union, 2007. European Communities (drinking water) No. 2 Regulations 2007. S.I. No. 278, Brussels, pp. 22-23.

Evgenidou, E., Fytianos, K., Poulios, I., 2005. Semiconductorsensitized photodegradation of dichlorvos in water using $\mathrm{TiO}_{2}$ and $\mathrm{ZnO}$ as catalysts. Appl. Catal. B. Environ. 59, 81-89.

Evgenidou, E., Konstantinou, I., Fytianos, K., Albanis, T., 2006. Study of the removal of dichlorvos and dimethoate in a titanium dioxide mediated photocatalytic process through the examination of intermediates and the reaction mechanism. J. Hazard. Mater. B137, 1056-1064.

Freeman, F., Kappod, J.C., 1985. Permanganate ion oxidations. 15. additional evidence for formation of soluble (colloidal) manganese dioxide during the permanganate ion oxidation of carbon-carbon double bonds in phosphate-buffered solutions. J. Am. Chem. Soc. 107, 6628-6633.

Gan, Q., Singh, R.M., Wu, T., Jans, U., 2006. Kinetics and mechanism of degradation of dichlorvos in aqueous solutions containing reduced sulfur species. Environ. Sci. Technol. 40, 5717-5723.

Gao, J., Liu, L., Liu, X., Zhou, H., Lu, J., Huang, S., Wang, Z., 2009. The occurrence and spatial distribution of organophosphorous pesticides in Chinese surface water. Bull. Environ. Contam. Toxicol. 82, 223-229.

Kozlova, E.A., Smirniotis, P.G., Vorontsov, A.V., 2004. Comparative study on photocatalytic oxidation of four organophosphorus simulants of chemical warfare agents in aqueous suspension. J. Photochem. Photobiol. Chem. 162, 503-511.

Lad, C., Williams, N.H., Wolfenden, R., 2003. The rate of hydrolysis of phosphomonoester dianions and the exceptional catalytic proficiencies of protein and inositol phosphatases. Proc. Natl. Acad. Sci. USA 100, 5607-5610.

Lieberman, M.T., Alexander, M., 1983. Microbial and nonenzymatic steps in the decomposition of dichlorvos (2,2-dichlorovinyl O, O -dimethyl phosphate). J. Agric. Food Chem. 31, 265-267.

Lu, M.C., Roam, G.D., Chen, J.N., Huang, C.P., 1993. Microtox bioassay of photodegrdation byproducts from photocatalytic oxidation of pesticides. Chemosphere 27, 1637-1647.
Lu, M.C., Roam, G.D., Chen, J.N., Huang, C.P., 1996. Adsorption characteristics of dichlorvos onto hydrous titanium dioxide surface. Water Res. 30, 1670-1676.

Lu, M.C., Chen, J.N., Chang, C.P., 1997. Effect of inorganic ions of the oxidation of dichlorvos insecticide with Fenton's reagent. Chemosphere 35, 2285-2293.

Lu, M.C., Chen, J.N., Chang, C.P., 1999. Oxidation of dichlorvos with hydrogen peroxide using ferrous ion as catalyst. J. Hazard. Mater. B65, 277-288.

Ma, J., Graham, N., Li, G., 1997. Effect of permanganate preoxidation in enhancing the coagulation of surface waters laboratory case studies. J. Water Supply Res. Technol. - Aqua $46,1-10$.

Macey, R.I., Oster, G.F., 2005. Berkeley Madonna. University of California, Berkeley, CA, USA.

Ministry of Environmental Protection of China, 1995. Water Quality-Determination of Acute Toxicity-Luminescent Bacteria Test. Beijing, China.

Ministry of Environmental Protection of China, 2002. Environmental Quality Standard for Surface Water. Beijing, China.

Ministry of Environmental Protection of China, 2008. Available from: http://www.sepa.gov.cn/law/gz/bmhb/gwygf/200805/ t20080526_123072.htm (accessed on 11.01.09).

Ministry of Public Health of China, 2006. Standard for Drinking Water Quality. Beijing, China.

Ohashi, N., Tsuchiya, Y., Sasano, H., Hamada, A., 1993. Screening on reactivity of organic pesticides with ozone in water and their byproducts. Jpn. J. Toxicol. Environ. Health 39, 522-533.

Qiang, Z., Adams, C., 2004. Determination of monochloramine formation rate constants with stopped-flow spectrophotometry. Environ. Sci. Technol. 38, 1435-1444.

Rodríguez, E., Majado, M.E., Meriluoto, J., Acero, J.L., 2007. Oxidation of microcystins by permanganate: reaction kinetics and implications for water treatment. Water Res. 41, 102-110.

Schramm, J.D., Hua, I., 2001. Ultrasonic irradiation of dichlorvos: decomposition mechanism. Water Res. 35, 665-674.

U.S. Department of Health, Education and Welfare, 1978. Bioassay of Trimethylphosphate for Possible Carcinogenicity. National Cancer Institute Carcinogenesis Technical Report Series No. 81, Maryland, USA.

U.S. Environmental Protection Agency, 2006. Interim Reregistration Eligibility Decision for Dichlorvos (DDVP). Washington D.C., pp. 123, 136-137.

Vlyssides, A., Barampouti, E.M., Mai, S., Arapoglou, D., Kotronarou, A., 2004. Degradation of methylparathion in aqueous solution by electrochemical oxidation. Environ. Sci. Technol. 38, 6125-6131.

Waldemer, R.H., Tratnyek, P.G., 2006. Kinetics of contaminants degradation by permanganate. Environ. Sci. Technol. 40, 1055-1061.

Wolfenden, R., Ridgway, C., Young, G., 1998. Spontaneous hydrolysis of ionized phosphate monoesters and diesters and the proficiences of phosphatases and phosphodiesterases as catalysts. J. Am. Chem. Soc. 120, 833-834.

Yan, Y.E., Schwartz, F.W., 2000. Kinetics and mechanisms for TCE oxidation by permanganate. Environ. Sci. Technol. 34, 2535-2541.

Zhang, Q., Qu, X., Wang, W., 2007. Mechanism of OH-initiated atmospheric photooxidation of dichlorvos: a quantum mechanical study. Environ. Sci. Technol. 41, 6109-6116. 